\title{
Child Abandonment: Historical, Sociological and Psychological Perspectives
}

\author{
Michael H. Burnstein, MD \\ Children's Psychiatric Hospital, Ann Arbor
}

\begin{abstract}
$A B S T R A C T$ : Even though the act of physical child abandonment is a relatively common occurrence, it remains an understudied social phenomena. It has been an act of parents since earliest times, but even in our modern enlightened society, children are still ejected from their homes and physically abandoned in frightening numbers. Even though attention has been directed toward the understanding and combating of the numerous variations of child abuse and neglect, the problem of physical abandonment is rarely discussed until sensationalistic news reports emerge to remind us that children are still left in parks or on street corners. To further understand this phenomena of child abandonment, this paper reviews the literature and examines the process from historical, sociological and psychological perspectives. This report looks to stimulate further interest in physical child abandonment and its precursor, psychological child rejection, as forms of child abuse and neglect which can and should be combated by proper psychiatric intervention.
\end{abstract}

This paper will center on the act of physical child abandonment, such as, the act of leaving a child in a park or in front of a hospital, with no intention of returning for that child. In this sense, we will discuss physical child abandonment as if the child was property which was abandoned by its owner.

Psychologically speaking, there are both conscious and unconscious motivations for physical child abandonment which must be addressed in order to understand what has led to the final act of physical abandonment. Therefore in studying the physical act of abandonment, we will look at the rejecting and/or ambivalent parent(s) from a psychological perspective. As will be discussed, interventions with high risk potentially child-abandoning parents, may prevent the final act and its impact on the child, the parents and society. We will begin by looking at the historical patterns of child abandonment.

Dr. Burnstein is a Clinical Instructor at Children's Psychiatric Hospital, Department of Psychiatry, University of Michigan Medical School, Ann Arbor, Michigan 48109. Requests for reprints should be directed to him. 


\section{Historical Patterns of Child Abandonment}

One need look no further than to familiar descriptions of ancient civilizations to see the early prevalence of child abandonment. Motivations differ, but the act has been present since the time of earliest man. For example, Moses was left by his mother in a conscious effort to save his life. In this example, there was abandonment, but for the safety of the child. Most physical abandonments are acts to rid oneself of a burden, such as seen in Oedipus, described by Sophocleas, as the first born son of parents who gave him up to a shepherd, instructing the shepherd to let the infant die of exposure on a mountain. The sequella of this abandonment has been imprinted in the minds of mental health professionals in virtually every western society. But not until many centuries later is the first psychological treatment (1801) of an abandoned child recorded by the noted French otologist, Jean-Marie Itard. Itard took great effort to treat and raise a found child who had previously raised himself among animals in the forest near Aveyron, France [1].

Child abandonment is historically first mentioned in relation to providing basic care for parentless children. A survey of the literature reveals the emergence of first residential home for such children in the fourth century, in Europe. In the fifth century, a similar center was organized by the Christian Church in Arles, France, to care for and to protect what were then referred to as "exposed infants" [2]. In the twelfth century, there are reports from Montpellier, France, where l'Ordre des Hospitaliers de St. Esprit was opened, specifically to care for abandoned infants. Beginning with the Poor Law of 1601 in England, which legislated minimal care for the poor, including children, society had taken an increasing, although still incomplete, interest in children. Gradually, the church of Louis XIV, influenced European society to form a number of hospitals for the increasing numbers of abandoned and found infants. In the United States, the first orphanages were founded by nuns in 1729 , to provide care for a group of children whose parents died in an Indian massacre [3]. The next mention of such a setting was in Milano, Italy (1734), where a house for "found infants" was opened. Around the same time, French organizations, based around the Catholic Church, influenced the society of French Canada, to establish the first Canadian homes for children without parents. These homes were established by Marie MargueriteLajemmerais in Montreal [2]. Numerous social agencies then developed throughout the remainder of North America during the 1800 s. 
From the ancient Greeks, the Hebrews and from Europe, we have accounts of physical abandonment. But history says little about the motivations for the physical abandonment or the psychological treatment of the child. What is known from history, is that the subsequent physical and psychological development of these abandoned children varied according to the specific circumstances, the nature of the motivations and the historic and political context in which the physical abandonment occurred. The cases passed down through history, were the most monumental and perhaps for that reason, their stories have been inscribed in the literature of mankind.

\section{Sociological Patterns of Child Abandonment}

A review of literature concerning physical child abandonment reveals that reports come from almost every region of Europe, but few from other geographic locations. One can speculate that physical abandonment is also present in non-Western cultures, but in this report, we will concentrate on data available from Western societies as described below.

From Italy, a study in 1967 of physically abandoned children, described the problems of their adoption and foster parenting, stating that social planning for the abandoned child has long been a social problem in that European country [4]. In 1972, a Belgium committee studied the social aspects of physical child abandonment and classified the motives for the causes of the actual abandonment. Three categories of abandoning mothers were described, with clinical examples of each given. In the first category, described as the most classical example, the mother found herself pregnant and was left by the father of the baby. In the second category, were those mothers who had very poor social and moral adjustment in early life and who had difficulty in accepting responsibility. The third group, included married women who abandoned their legitimate babies born from extramarital affairs. The study concluded that even though physical child abandonment is frequent and can be classified in general terms, there are in fact, many different forms of actual abandonment [5]. In 1972, a Canadian study detailed historically, the lives of physically abandoned children in both the French-Canadian Catholic and the EnglishCanadian Protestant societies of Canada. This study concluded that abandonment of children had been a major social problem in both of these divergent North-American cultural and religious groups for over two centuries $[2,6]$. 
A Czechoslovakian study in 1972, documented that an unusually high occurrence of somatic problems occurred in abandoned children admitted to a child's residential village [7]. The problems of physically abandoned children were further studied in France in 1973 [8] and in Poland in 1974 [9], where the role of the pediatrician in the diagnosis and prevention of socially deprived and rejected children was recommended and encouraged. In 1974, a report from Italy reviewed the fate of children of unknown parents, born between 1934 and 1971, in the province of Rome. This study pointed out the high incidence of social and psychological mal-adjustment found in these children [10]. In 1975 , a report from Hungary outlined the problems of physically abandoned infants in that country and their subsequent placement into institutions. The report concluded that the psychological problems of the abandoned children studied were severe but that they varied according to the various regions of that country [11] (a finding that was difficult to interpret).

\section{Psychological Factors}

Most children abandoned early in life are raised for years in orphanages and foundling homes. These institutions often lack the individual attention and stimulation that children need for proper development. Province and Lipton [11], observing infants directly, have documented the severe damage to the personality, specifically to the ego and intellectual development, resulting from development under conditions of deprivation and understimulation. Timing of the rejection or abandonment is crucial, as it is known that the nature of the impact of maternal deprivation will be greatest in infants ranging from a few days or weeks to one and a half years of age. The second most endangered group concerns those children between age one-anda-half to two-and-a-half or three years of age [12]. Of course, the ejection of a child during the height of his Oedipal struggles may certainly leave lasting scars, and one must evaluate each specific case as to the nature of the alternative parenting and available stimulation.

With this in mind, let us review what has been reported about child rejection and abandonment as concerns its psychological vicissitudes.

Psychoanalytic studies primarily relate psychological rejection and physical abandonment to the theory of object loss. Bowlby [13] attempt to explain that the loss of the mother in the young child is similar to the loss in an adult of a loved object. Recent studies of child rejection and abandonment[14] conform Bowlby's findings, that the 
child's thoughts and behavior are still directed towards the love object, and that hostility, appeals for help, despair, withdrawal, regression, disorganization and reorganization of behavior directed toward a new object are often seen. Nagera [15] reported on a child's reaction to the death of important objects and concluded that massive denial, search for substitutes and fantasies of reunion are quite common. The literature seems to confirm that this same process is common in abandoned children $[14,16]$.

A major contribution to the psychoanalytic understanding of rejection and abandonment was Rochlin's [16] paper titled, "The Dread of Abandonment: A contribution to the Etiology of the Loss Complex and Depression," written in 1961 [16]. Rochlin felt that, in the child's emotional development, in which the formation of meaningful relationships is the principal psychic process, there rests the matrix of the dread of abandonment. Rochlin thus considers the dread of abandonment as a normal process and then discusses why loss should have such a profound influence throughout life.

Most therapists use the term "object loss" to mean, a desired relationship to another person who had to be abandoned. But the object loss is a very specific type of object loss for the physically abandoned child, in that both psychologically rejected and physically abandoned children, after a certain age, are cognitively aware of the fact that they were unwanted and/or rejected and discarded. Not only do their egos have to deal with the impact of the specific object loss, but in the case of actual abandonment, it must deal with the abandonment itself. More specifically, the abandoned child's ego must deal with the conscious and unconscious thoughts that he was rejected because he was no good, did something wrong, had been interfering, etc. The specific personality characteristics of abandoned children noted above, are rooted in their complex past, and are the observable signs of their ego's attempts to deal with both the loss and/or the awareness of having been abandoned.

From the material presented above, one may assume that abandoned children are at high risk for psychological disturbance. This appears to be substantiated by the available studies on the psychological sequella of abandonment, which are rather limited both in number and in detail. This can be seen clearly in the studies outlined below which confirm psychological deviance in the children but do not specify whether the disturbances seen are reactive or enduring.

One such study was by Childers [17] who found abandoned children to be relatively "more hypersensitive," due to the insecurity of not belonging to a permanent setting. 
Numerous authors have related aggressive behavior in children to the psychological rejection and the abandonment which followed. These reports note rebelliousness, disobedience, temper tantrums, stealing and truancy. Symonds [18] found psychologically rejected children to be uncommunicative, rebellious, less friendly and bewildered about life. A more recent study on consciously rejected and physically abandoned children by Pemberton [19] defines a symptom complex of aggression, rejecting attitudes to parents, negativistic attitudes, stealing, lying and encopressis. The parents in this study were found to have unstable marriages and that instability antedated the actual abandonment of the child.

Other similarities were found in the parents of abandoned children. Newell [20] studied motivations for child rejection and abandonment and found that it was primarily due to the mother's unhappy adjustment to marriage, which usually was the result of immaturity and emotional instability. A recent psychoanalytic study by Burnstein [14], confirms this finding by reporting the intensive treatment of a physically abandoned child and a consciously rejecting mother. This mother, was extremely immature, emotionally unstable and unable to positively relate to the child, as the child represented to the mother the unacceptable aspects of the mother herself.

\section{Recommendations}

A number of recommendations are derived from the above review of historical, sociological and psychological study of child abandonment. The recommendations are:

1. Since physical child abandonment is relatively frequent occurrence which has basically been neglected by society, efforts should be made to educate child health professionals and social agencies about this phenomena.

2. The subject of child abandonment should therefore be introduced in curricula for students of all medical and mental health disciplines i.e., nurses, physicians, social workers, etc.

3. Professionals of all disciplines should be aware of the signs of possible abandonment and should maintain a high index of suspicion when the following is observed: (a) mothers who have not been able to positively cathect the child and who view their child as a burden; (b) mothers with a history of difficulty accepting responsibility along with a history of poor emotional adjustment; 
(c) a pregnant woman with few supports by the future father, (d) off-spring of extramarital relationships, (e) unwanted pregnancy in an extremely unstable marriage, (f) an extremely aggressive, rebellious, disobedient child with a history of stealing and truancy.

4. Keep in mind that the criteria listed above are increasingly significant as they occur in clusters and that the same factors may lead to other forms of child abuse and neglect instead of abandonment.

5. Early intervention may be the only form of prevention. An inquiry into the mothers feelings about parenting may lead to the mother sharing sensitive personal information about her wish to rid herself of the burden (child). Relief may follow with the subsequent establishment of a helpful therapeutic relationship.

6. Offer help without being critical if thoughts of abandonment emerge. Don't be afraid to inquire about these sensitive issues.

7. Supportive psychotherapeutic interventions may help the parent reinvest in the child, find alternative living arrangements for the child within the family, or aid in making proper arrangement for foster placement.

8. When working with abandoned children, one must address the critical issues which are frequently present. This may prevent deviant psychological sequella. Important issues to be addressed are feelings regarding the loss, rejection, abandonment, etc.

9. Abandoned children should be followed closely by mental health professionals in order to ascertain whether symptoms such as aggression and despair are reactive or enduring. Psychotherapeutic interventions should be instituted as needed.

Psychological rejection and the subsequent physical abandonment of children by their parents should be considered as major social problems which should be further studied by mental health professionals, sociologists and public health officials. The impact of the physical abandonment on the development of these children and upon society should be given due consideration, commensurate with its importance.

\section{Conclusion}

Historical, social and psychological aspects of physical child abandonment and its precursor, psychological rejection of the child, have been presented. Physical child abandonment has been described as occurring universally in the Western world and probably also in the non- 
Western world. More studies of physical abandonment have been reported from Europe than from the United States, suggesting that European countries have given this specific social problem a higher priority than has this country. Psychological studies suggest a specific set of behaviors seen in abandoned children such as aggressiveness, rebelliousness and disobedience. These behaviors can best be understood in the psychoanalytic framework of object loss, that is, if the abandonment itself is considered a specific unique type of object loss, where the child is consciously aware that his parent(s) psychologically rejected him and then physically abandoned him. Personality and family characteristics of consciously rejecting and physically abandoning mothers have been reported, which may be helpful in instituting preventive psychiatric intervention. Recommendations for prevention and intervention have also been presented.

\section{References}

1. Harrison S: Child psychiatry: Residential treatment. In A Freedman, H Kaplan, and B Sadock (Eds) Comprehensive Textbook of Psychiatry, Second Edition, 1975.

2. Fortier B: Foundlings in French-Canada (I) (1775-1959). Union Med Can 101: 715-720, 1972.

3. Lewis M, Solnit A: Residential treatment. In A Freedman, H Kaplan, and B Sadock (Eds) Comprehensive Textbook of Psychiatry, Second Edition, 1975.

4. Bianchi Z: Problems of abandoned children, adoption of foster parents. Minerva Nipiol 17: 13-28, 1967.

5. Barthelemy J: Social aspects of child abandonment. Rev Med Liege 27: 414-418, 1972 .

6. Fortier B: Foundlings in French Canada (II) 1869-1935. The Protestant Infants Home. Union Med. Canada 101: 715-720, 1972.

7. Dunausky J: Somatic changes in children admitted to a children's village. $C A S$ LEK CESK 111: 1181-1185, 1972.

8. The social problem child, round table discussion of the French child neuropsychopath: Study group. Rev Neuropsychiatr Inf 21: 204-216, 1973.

9. Blain A: The role of pediatricians in the diagnosis and prevention of socially deprived children. Pediatric Pol 26: 945-949, 1974.

10. Menichella V: The fate of children of unknown parents born between 1934 and 1971, in the province of Rome. Minerva Pediatr 26: 1945-49. 1974.

11. Provence S, and Lipton R: Infants in institutions. New York: New York University International Press, 1962.

12. Nagera H: Day care centers: Red light, green light, amber light. Int Rev Psychoanal 2: 121-137, 1975.

13. Bowlby J: Grief and mourning in infancy and early childhood. Psychoanal Study Child 15: 679-688, 1960.

14. Burnstein $M$, Colman $M$ : The residential treatment of a consciously rejected child: A pshchoanalytic study with social and legal implications. Child Psychiatry Dev 10: $222-231,1980$.

15. Nagera H: Children's reaction to death of important objects: A developmental approach. Psychoanal Study of Child 25: 288-309, 1953. 
16. Rochlin G: The dread of abandonment: A contribution to the etiology of the loss complex and to depression. Psychoanal Study Child 15: 451-470, 1961.

17. Childres M: Hyperactive children having behavior disorders. Amer J Orthopsychiatry 5: 227-243, 1935.

18. Symonds P: A study of parental acceptance and rejection. Amer $J$ Orthopsychiatry 4: $679-688,1938$.

19. Pemberton DA, Benady DR: Consciously rejected children. Brit J Psychiatry 123: 575-578, 1973.

20. Newell N: "Psychodynamics of Maternal Rejection." Amer J Orthopsychiatry 4: 387-401, 1934. 